\title{
Produção de conhecimento interdisciplinar: contextos e pretextos em programas de pós-graduação
}

\section{Interdisciplinary knowledge production: contexts and pretexts for graduate programs}

\section{La producción de conocimiento interdisciplinario: contextos y pretextos en programas de posgrado}

Marlize Rubin-Oliveira, doutora em Educação pela Universidade Federal do Rio Grande do Sul e professora do Programa de Pós-Graduação em Desenvolvimento Regional (PPGDR) da Universidade Tecnológica Federal do Paraná (UTFPR). E-mail: rubin@utfpr.edu.br.

Maria Estela Dal Pai Franco, doutora em Educação pela Universidade Federal do Rio Grande do Sul (UFRGS) e professora titular do Programa de Pós-Graduação em Educação (PPGEdu/ Faced) da Universidade Federal do Rio Grande do Sul. E-mail: medalpaifranco@ufrgs.br.

\section{Resumo}

O objetivo central deste artigo foi analisar programas de pós-graduação interdisciplinares, buscando captar especificidades dos contextos e pretextos dos programas confrontados. O locus do estudo foram oito programas de pós-graduação (stricto sensu) interdisciplinares reconhecidos e recomendados pela Coordenação de Aperfeiçoamento de Pessoal de Nivel Superior (Capes), que têm como princípio o diálogo entre Ciências Humanas e da Natureza e um programa da University of Arizona ( $U$ of $A$ ), dos Estados Unidos. As análises realizadas identificaram uma relação estreita entre movimentos internacionais de repensar a ciência moderna e a gênese dos programas. Os programas são compreendidos como parte do movimento crescente da ciência que busca repensar a fragmentação 
e a dualidade, inclusive na direção de legitimar outros espaços de poder e prestígio e rever a organização de áreas do conhecimento historicamente constituídas.

Palavras-chave: Produção de Conhecimento. Interdisciplinaridade. Pós-Graduação.

\section{Abstract}

The main goal of this paper was to analyze interdisciplinary graduate programs, seeking to capture the specific contexts and pretexts confronted by them. The locus of the study were eight interdisciplinary graduate programs accredited and recommended by Brazilian Federal Agency for Support and Evaluation of Graduate Education (CAPES), based on the principle of dialogue between the humanities and the natural sciences and a program at the University of Arizona ( $U$ of A) - United States. The analyses identified a close relationship between international movements to rethink modern science and the genesis of the programs. The programs are understood as part of the growing movement of science that seeks to rethink fragmentation and duality and to consider other legitimate positions of power and prestige along with the revision of the organization of knowledge in historically constituted areas.

Keywords: Knowledge Production. Interdisciplinarity. Graduate Programs.

\section{Resumen}

El objetivo central de este artículo fue analizar programas interdisciplinarios de posgrado, buscando captar especificidades de los contextos y pretextos de los programas confrontados. El locus del estudio fueron ocho programas de posgrado (stricto sensu) interdisciplinarios reconocidos y recomendados por la Coordinación de Perfeccionamiento de Personal de Nivel Superior (CAPES), cuyo principio es el diálogo entre las Ciencias Humanas y de la Naturaleza, y un programa de la University of Arizona ( $U$ of $A$ ) - Estados Unidos. Los análisis llevados a cabo identificaron una estrecha relación entre 
los movimientos internacionales de repensar la ciencia moderna y la génesis de los programas. Se comprenden los programas como parte del creciente movimiento de la ciencia que trata de repensar la fragmentación y la dualidad, incluso en el sentido de legitimar otros entornos de poder y prestigio y revisar la organización de áreas de conocimiento históricamente constituidas.

Palabras clave: Producción de Conocimiento. Interdisciplinariedad. Posgrado.

\section{Introdução}

A produção de conhecimento interdisciplinar é um desafio que se coloca à ciência. Ao longo da construção humana, a ciência foi se diferenciando das demais formas de produção de conhecimento, pelo rigor do método, sendo ela alicerçada principalmente na divisão disciplinar, processo esse que marcou a modernidade.

A novidade trazida pelo pensamento científico moderno, como aponta Raynaut (2011), foi aceitar dividir o mundo em facetas ou níveis de organização diferentes e tentar desenvolver instrumentos específicos - conceitos, definições de objetos e métodos de observação entre outros. Foi esse reducionismo que possibilitou a produção de um conhecimento que permitisse uma ação mais decisiva sobre o mundo. Isso quer dizer, ainda nas palavras do autor, que o recorte do real pelas disciplinas foi o movimento histórico do pensamento humano que viabilizou o surgimento e o desenvolvimento do pensamento científico.

Assim, é inegável que tenhamos herdado a divisão disciplinar como forma de produção de conhecimento científico. Mesmo compreendendo que essa divisão fora arbitrária e historicamente situada - para o que Raynaut (2011) chama a atenção -, ela está na gênese daquilo que conhecemos hoje por ciência. Entretanto, também há um razoável consenso a respeito da porosidade das fronteiras das disciplinas. É possível perceber o movimento de criação de novas disciplinas a partir do alargamento das fronteiras ou da convergência 
de duas ou mais disciplinas, a exemplo da Biotecnologia e da Ecologia, entre outras. Para Bourdieu (1983), é nas disciplinas, dentro do campo científico, que está de fato o grau de autonomia.

Hoje, é possivel perceber que a solução de problemas cada vez mais complexos passa necessariamente pela diversificação de iniciativas e das formas de pensar e de agir, principalmente no que tange à produção do conhecimento científico. Os programas de pósgraduação interdisciplinares têm se mostrado como espaço de produção de conhecimento que busca ultrapassar as fronteiras da organização acadêmica e de conhecimentos disciplinares historicamente constituídos - e foi de tais experiências que este artigo se ocupou. 0 objetivo foi analisar programas de pós-graduação interdisciplinares, buscando, no processo, captar especificidades dos contextos e pretextos dos programas confrontados. O locus do estudo foram oito programas de pós-graduação (stricto sensu) interdisciplinares reconhecidos e recomendados pela Coordenação de Aperfeiçoamento de Pessoal de Nivel Superior (Capes), que têm como princípio o diálogo entre Ciências Humanas e da Natureza e um programa da University of Arizona ( $U$ of $A$ ), dos Estados Unidos. Para tanto, foram examinados documentos, bem como realizadas entrevistas com coordenadores e ex-coordenadores dos programas. Registra-se que o estudo é parte de um trabalho de tese desenvolvido no Programa de Pós-Graduação em Educação da Universidade Federal do Rio Grande do Sul (PPGEdu / UFRGS) e da participação no Programa de Visiting Scholar ( $U$ of A), bem como de uma pesquisa interinstitucional desenvolvida no âmbito do Observatório da Educação (Obeduc), da Capes e do Instituto Nacional de Estudos e Pesquisas Educacionais Anísio Teixeira (Inep), concluída em 2013.

Como material empírico para análise, foram utilizados, no contexto brasileiro, o Documento de Área da Comissão de Área Interdisciplinar (CAPES/CAINTER, 2009), disponivel no portal da Capes, no link Caderno de Indicadores, entrevistas com coordenadores e/ou ex-coordenadores dos programas e as suas propostas. No que se refere ao programa da $U$ of $A$, foram acessados documentos disponiveis na página Graduate Interdisciplinary Programs (GIDP, 2009). A análise de 
conteúdo foi utilizada como recurso analítico, pautada principalmente nas duas categorias previamente estabelecidas: contextos e pretextos. Dessa forma, buscou-se perceber o processo social e histórico de implementação e consolidação dos programas e, assim, identificar as principais motivações dos sujeitos envolvidos na elaboração das propostas dos programas.

O texto está organizado em três seções, além da Introdução. A primeira busca compreender a universidade como espaço de produção e assimilação de conhecimento. A segunda seção trata da implementação e consolidação dos programas, com foco na compreensão daquilo que se denominou de contextos e pretextos. Nessa seção, a opção foi a de apresentar alguns excertos das entrevistas realizadas. Para tanto, fez-se uso de indicações 11,12 e assim por diante, para preservar o anonimato dos interlocutores. Os excertos das propostas são identificados com P1, P2 etc. Por fim, as Considerações finais buscam elencar os principais achados da pesquisa.

\section{Universidade e pós-graduação: espaço de produção e assimilação de conhecimento}

A tentativa de ultrapassar as lógicas simplistas de compreensão da produção de conhecimento dentro dos espaços universitários requer, por um lado, reconhecer a universidade como um locus privilegiado de produção de conhecimento científico e admiti-lo como não neutro. Dessa forma, ela também é legitimadora de modelos de fazer ciência nem sempre explicitados. Essa aspiração requer, por outro lado, reconhecer-se que, nesse espaço, há lugar para refletir e propor práticas que buscam mudanças no fazer e no pensar a ciência.

Dentro do contexto de consolidação e legitimação dos pressupostos da ciência moderna, a universidade desempenhou um papel de destaque. A luta histórica pela valorização e pela legitimação da ciência contra o obscurantismo da Idade Média encontrou nas universidades um espaço de contestação. Tal análise não impede o reconhecimento de tantos outros espaços legítimos nesse processo. 
No entanto, a universidade como espaço "privilegiado da produção de alta cultura e conhecimento científico avançado é um fenômeno do século XIX, do período capitalista liberal, e o modelo de universidade que melhor traduz é o modelo alemão, da Universidade de Humboldt" (SOUSA SANTOS, 1997, p. 193).

O autor identificou três tensões vividas pela instituição universidade e três crises emanadas dessas tensões. A primeira tensão, entre produção de alta cultura e conhecimentos úteis para as tarefas de transformação social, desencadeou uma crise de hegemonia. A universidade vive essa crise na medida em que sua incapacidade para desempenhar funções contraditórias leva os grupos sociais mais atingidos a procurarem meios alternativos. A segunda tensão, entre hierarquização e democratização, manifesta-se como crise de legitimidade. "A universidade sofre uma crise de legitimidade na medida em que se torna socialmente visivel a falência de seus objetivos coletivamente assumidos" (SOUSA SANTOS, 1997, p. 190). Para ele, a terceira tensão, entre autonomia institucional e produtividade social, manifesta-se como crise institucional: "a universidade sofre uma crise institucional na medida em que sua especificidade organizativa é posta em causa e se the pretendem impor modelos organizativos vigentes noutras instituições tidas por mais eficientes" (1997, p. 190).

As tensões e as consequentes crises identificadas por Sousa Santos (1997) podem ser entendidas como parte do movimento de tensões e crises do modo de pensar e fazer conhecimento com base nos pressupostos da modernidade. Dizer que o modelo está em crise seria uma afirmação aligeirada e, talvez, ingênua. O que se observa, entretanto, dentro da universidade, são crescentes movimentos que buscam repensar a fragmentação e a dualidade, inclusive como forma de legitimar espaços de poder e prestígio e de rever o próprio conceito de legitimidade.

O conhecimento produzido no seio das universidades representa um espaço legítimo de poder, definindo limites e prioridades para os que o dominam. A fragmentação do conhecimento, legitimada nos departamentos, confere aos indivíduos instâncias de poder e 
autonomia. O conceito de campo científico discutido por Bourdieu (1983, p. 122) ajuda na compreensão da ideia de espaços de poder dentro das universidades:

O campo científico, enquanto sistema de relações objetivas entre posições adquiridas (em lutas anteriores), é o lugar, o espaço de jogo de uma luta concorrencial. O que está em jogo especificamente nessa luta é o monopólio da autoridade científica definida, de maneira inseparável, como capacidade técnica e poder social [...], compreendida enquanto capacidade de falar e agir legitimamente (isto é, de maneira autorizada e com autoridade), que é socialmente outorgada a um agente determinado.

A legitimidade do conhecimento produzido nas universidades consolida também uma forma de ensinar e aprender e retroalimenta a produção científica. Dessa forma, o processo de ensinar e aprender reveste-se de neutralidade científica, como se o fazer, na universidade, estivesse alheio a interesses e despojado de vaidades. Tal concepção consolida, ou busca consolidar, o modelo de conhecimento sempre positivo, em nome do progresso e da formação profissional.

Reflexões sobre os principais pressupostos da ciência moderna, principalmente aqueles pautados na neutralidade, na dualidade e na fragmentação, fazem compreender que a ideia de conhecimento positivo, acima das ambições humanas, não é apenas uma forma ingênua de perceber a produção de conhecimento, mas também uma forma de legitimação, dominação e poder. O conhecimento que se inscreve na busca da autonomia deve, em primeiro lugar, reconhecerse como profundamente imbricado das relações que estabelecem. Dessa forma, ele se reconhece como histórico e socialmente produzido, dependente das condições de sua produção.

Essas reflexões são importantes para a compreensão do processo de produção de conhecimento que é legitimado nas universidades. No entanto, é preciso reconhecer a universidade também como espaço de proposição e prospecção. A universidade tem se consolidado como espaço importante para iniciar movimentos de reflexão, propondo caminhos que vão da criação de cursos à 
constituição de núcleos de pesquisa, do estímulo à cultura crítica em relação ao Estado à crítica à avalanche mercadológica. Ela gesta a crítica no âmago de seu caráter instituinte e instituído. Ao mesmo tempo em que produz conhecimentos, ela se transforma e abre espaços para a crítica sobre o modelo de ciência dominante. Dessa forma, exerce um papel tanto de resistência quanto de acomodação e legitimação de modelos. A perceptiva de resistência - tomada emprestada de Giroux (1986) - deve ter uma função reveladora e crítica da dominação. Deve fornecer oportunidades teóricas para a autorreflexão, possibilitando autoemancipação e emancipação social.

A produção de conhecimento que visa à resistência possibilidade teórica de autorreflexão - a visões dominantes pode encontrar na universidade um terreno fértil para reflexão e enfrentamento de algumas das tensões colocadas pelos processos homogeneizadores e padronizadores. As mudanças no modo de produção de conhecimento e aquelas decorrentes da criação de novos saberes têm, nos espaços das universidades, a possibilidade de gerar saberes críticos, propositivos e prospectivos.

Bordas (2007, p. 74), refletindo sobre a produção do conhecimento no espaço das instituições universitárias, chama a atenção para o fato de que

\begin{abstract}
Tornar concreta uma perspectiva inovadora nessas instituições é um empreendimento complexo e difícil, pois implica enfraquecer ou mesmo romper padrões de pensamento e ação fortemente estabelecidos e instaurar algumas condições básicas, institucionais ou relativas aos agentes que nela atuam, que assegurem a possibilidade e a continuidade de uma mudança na própria visão da missão que the cabe.
\end{abstract}

Para o autor, se desconfiamos das certezas totalizantes da racionalidade moderna, precisamos seguir acreditando em mudanças localizadas que superem condições igualmente localizadas, instituídas em contextos que guardam alguma autonomia e reúnem pessoas capazes de propor inovações.

Em síntese, o que se pode perceber é que a universidade sustentada pela racionalidade instrumental construiu uma ótica 
pragmática e tecnocrata que foi definhando seu potencial sociopolítico e cultural e privilegiou seu conteúdo utilitário, produtivista e individualista. As tensões entre os conhecimentos produzidos na universidade e as demandas da maioria das sociedades podem ser mobilizadoras de uma perspectiva de contraponto entre a dualidade e a fragmentação no fazer científico. Dessa forma, compreender os contextos e pretextos (local e global) que se delinearam na gênese de alguns programas pode contribuir para avançarmos na construção de propostas interdisciplinares e, principalmente, na produção de conhecimento interdisciplinar.

\section{Implementação e consolidação dos programas: contextos e pretextos}

Na análise do processo de implementação e consolidação dos programas foi possivel identificar duas motivações (pretextos) principais que se destacam nos dois contextos analisados - o brasileiro e o norte-americano -, resguardadas as respectivas especificidades: as mudanças no fazer científico e a experiência do corpo docente.

O primeiro fator é o ligado às mudanças no fazer científico, abrangendo o pensar e o agir a partir da crítica ao modelo de ciência que, com sua base na modernidade, pressupõe uma natureza reversivel, a dicotomia entre Ciências Humanas e da Natureza e a fragmentação do objeto de estudo (descontextualização). Tal modelo é considerado insuficiente no enfrentamento das chamadas mudanças globais em que o caminho proposto pelos programas é o diálogo entre Ciências Humanas e da Natureza e em que a interdisciplinaridade se coloca principalmente como meta, e o diálogo entre saberes, como necessidade teórico-metodológica.

A crítica ao processo de construção de conhecimento científico com base na dualidade e na fragmentação, no campo das ciências ambientais, ganhou força e se consolidou no Brasil principalmente a partir da realização da II Conferência das Nações Unidas sobre Meio Ambiente e Desenvolvimento, também conhecida por Rio-92. A 
questão central que se colocava naquele momento era a possibilidade de se construir outro modelo para a relação da humanidade com a natureza e a ideia de outro modelo de desenvolvimento. A ll Conferência, realizada em 1992, foi um momento de ebulição de ideias gestadas em décadas anteriores. 0 pioneirismo da Conferência de Estocolmo, com o tema Meio Ambiente e Desenvolvimento, e de alguns trabalhos, como o de Rachel Carson intitulado "A primavera silenciosa”, lançado em 1962 e no qual a autora apresentou um questionamento nos Estados Unidos acerca do modelo agrícola convencional e de sua crescente dependência do petróleo como matriz energética (CARSON, 2002), serviram de inspiração para a II Conferência, realizada no Brasil.

Esse caudal de movimentos sociais, políticos, econômicos e científicos serviu de inspiração e base, tanto teórica quanto institucional, para a implementação dos programas. Muito embora apenas dois desses programas tenham iniciado suas atividades na década de 1990 - os demais começaram as primeiras turmas nos anos 2000 -, os relatos dos interlocutores destacam as primeiras iniciativas de construção das propostas (reuniões, grupos de pesquisa e ações institucionais) ainda na década de 1990. No que tange às questões ambientais, aquela década foi marcada por conquista de espaço e de visibilidade, tanto no âmbito acadêmico quanto no âmbito político. No Brasil, a realização da Rio-92 foi um marco importante no relato dos interlocutores para a criação de vários dos programas aqui em pauta. Um dos programas analisados nasceu da iniciativa de um então reitor a partir da criação de um espaço institucional com vistas à participação da universidade na Conferência. Dessa forma, a proposta da criação do programa interdisciplinar surgiu também alavancada pelas várias experiências dos professores envolvidos na Rio-92.

Nos excertos das entrevistas realizadas percebe-se a influência da Conferência na elaboração das propostas dos programas. Fica explícito o movimento dos professores/pesquisadores em torno das questões ambientais voltadas à sustentabilidade, bem como à presença de pressupostos da interdisciplinaridade: 
O programa nasceu da iniciativa do reitor com a intenção de organizar a participação da universidade na Conferência do Rio de Janeiro (I-2).

A Eco-92 foi um momento de ebulição que legitimou o desejo de alguns profissionais que estavam dentro das instituições e não tinham um programa interdisciplinar de pesquisa (I-8).

Nós nos conhecemos e iniciamos as discussões em torno da questão ambiental, estávamos todos sob o impacto da Eco-92. Tínhamos uma crítica ao modelo de agricultura insustentável, e a questão fundamental era: outro modelo de agricultura é possivel (I-4).

Na fala dos interlocutores é possivel perceber que a Conferência foi um dos grandes movimentos constitutivos presentes na gênese dos programas. As ações em torno da Conferência serviram para alavancar projetos embrionários já existentes no contexto das universidades. Os programas tiveram grupos de professores/pesquisadores que, de alguma forma, integraram discussões em âmbito mundial, construíam críticas ao fazer científico da modernidade, que tem a fragmentação e a dualidade como premissas - principalmente no campo das ciências ambientais -, e encontraram um espaço político de discussão em grandes conferências internacionais, como no caso da Rio-92. 0 questionamento da ciência fragmentada toma corpo, no Brasil, na especificidade de um contexto de pós-graduação fortemente regulado por políticas públicas e por um sistema de avaliação no qual subjaz a própria avaliação da educação superior do País.

No que tange ao pretexto de mudança no fazer científico, no contexto da $U$ of $A$, cabe lembrar que o Interdisciplinary Doctoral Minor in Global Change se estruturou em 1994 no contexto do Graduate Interdisciplinary Programs (GIDP). O GIDP é um espaço institucional que agrega 14 programas interdisciplinares, que se constituem como parte integrante da Missão da Universidade do Arizona. De acordo com dados da universidade (GIDP, 2009), em 2008, os GIDPs formaram 10\% dos Ph.D. da Universidade do Arizona. O GIDP se orgulha da excelência acadêmica dos professores, a qual é reforçada pelas parcerias com os 
institutos de pesquisa e departamentos acadêmicos da universidade. Atualmente, cerca de 700 professores de 14 colleges estão ativamente envolvidos no GIDP. Na perspectiva do GIDP, fortalecer a rede de relações de cooperação significa pôr em prática a interdisciplinaridade na produção de conhecimento no contexto dos programas.

Na gênese do Global Change estão pesquisas sobre sustentabilidade desenvolvidas desde a década de 1970. Na perspectiva do interlocutor, foram o trabalho e as ideias visionárias de uma pesquisadora que convenceram a administração da universidade ( $U$ of $A$ ) a lançar um programa dentro de um instituto, chamado ISPE - Institute for the Study of Planet Earth. "Na época, como qualquer tipo de trabalho visionário e inovador, foi marginalizado, ficando sem espaço próprio no campus. Assim, foi alojado em uma casa doada distante do centro da universidade" (I-9).

O programa hoje tem como missão ajudar a formar e preparar a comunidade científica interdisciplinar que irá contribuir para uma compreensão integrada das dinâmicas naturais e sociais da mudança global. Ao mesmo tempo, o programa destina-se a criar um fórum no qual os estudiosos de diferentes partes da universidade podem se aglutinar de forma inovadora em torno dos problemas complexos que constituem a mudança global (GIDP, 2014).

Hoje, o programa integra o GIDP e ocupa lugar privilegiado, tanto no espaço físico da universidade quanto no financeiro. Isso é explicitado na fala do interlocutor:

Inicialmente, o ISPE ficou em uma casa, mas com corpo docente que tinha essa visão interdisciplinar, principalmente na área de pesquisa. Os projetos de pesquisas que passassem pelo instituto iriam angariar fundos, uma parte do valor do projeto, como modelo financeiro também. Então, o ISPE andou com um certo apoio também da administração da universidade, fazendo projetos e ganhando uma certa credibilidade acadêmica no exterior da universidade, nacionalmente (I-9). 
O que se pode perceber é que a experiência e a iniciativa dos professores, aliadas aos movimentos, reuniões e conferências internacionais em torno das questões ambientais, foram fundamentais para a institucionalização e o reconhecimento dos programas analisados. As pesquisas interdisciplinares, com foco nas relações sociedade/natureza, que existiam a partir de esforços de grupos de professores, muitas vezes marginalizados, passaram a ganhar espaço na efervescência dos movimentos locais e globais.

Como pode ser observado, as aproximações dos pretextos em pauta, quando confrontadas, pelas normas avaliativas, guardam as especificidades do contexto regulador brasileiro e do contexto de autonomia usufruído nas IES dos Estados Unidos, cujos laços de regulamentação são tecidos pelos indicadores de tipos institucionais e suas relações com a pesquisa e as agências governamentais ou não que as financiam.

O segundo pretexto ligado aos contextos se refere à experiência do corpo docente. Em ambas as realidades, os programas contam com grupos de professores com experiência e trajetória acadêmica disciplinar, muitos deles expoentes em suas áreas de atuação, em programas consolidados em áreas disciplinares, mas com trajetórias de pesquisa multi e interdisciplinar. Há de se resguardar, no entanto, o fato de que ter expoentes num contexto no qual mais de uma centena de universidades são consideradas as melhores do mundo (EUA) é diferente do contexto em que apenas algumas aparecem nos rankings mundiais (Brasil).

Outro fator que ficou evidenciado no caso brasileiro foi a influência das políticas de ciência e tecnologia e das políticas de pósgraduação. Dois aspectos foram marcantes: o primeiro é o de que, dos oito programas analisados, seis integram núcleos e/ou programas de pesquisa institucionalizados no âmbito das universidades a que pertencem. A maioria desses espaços nasceu sob a influência da institucionalização do Diretório dos Grupos de Pesquisa do CNPq, criado no início da década de 1990. O segundo aspecto é o de que todos os programas têm em seu interior grupos de pesquisa consolidados. 
O crescimento dos grupos de pesquisa é visto por vários pesquisadores da área da educação superior como uma das tendências marcantes na história do sistema de educação superior no Brasil. Essa tendência levou Morosini e Franco (2000) a identificarem três fases de expansão no Brasil: a de expansão das instituições, a de expansão dos cursos e a de expansão do sistema como um todo.

Franco (2009), ao analisar a trajetória dos grupos de pesquisa dentro da UFRGS, verificou um crescimento de $174,1 \%$ no decorrer do período de 1993-2008, o que demonstra a marcante expansão a partir da criação do diretório, bem como a participação de grupos em redes mais amplas, regionais, nacionais e até mesmo internacionais. A autora chama a atenção para a força dos grupos de pesquisa na construção do conhecimento científico e o papel que eles têm desempenhado no interior dos programas de pós-graduação, construindo e alicerçando as linhas de pesquisa.

A experiência dos programas analisados é bastante diversa do ponto de vista dos grupos de pesquisa. Há experiências relatadas de grupos que ajudaram a construir os programas que até mesmo serviram de base teórico-epistemológica. Também há relatos de grupos pouco experientes que não irão se sustentar dentro dos padrões de avaliação ou dos padrões de certificação das universidades, orientados pelos critérios tanto do CNPq quanto da Capes para a avaliação da pós-graduação. Um dos interlocutores relatou a existência de grupos compostos apenas por um professor/pesquisador e seus orientandos. Ou seja, mesmo com a larga experiência do corpo docente, parece haver, em alguns casos, a necessidade de ajustes, principalmente no que se refere à importância dos grupos de pesquisa na construção da multi e da interdisciplinaridade.

Outra experiência que se destaca é a de um programa que nasceu dos esforços de um grupo de professores/pesquisadores para consolidar uma área de conhecimento que, por diversas razões, não encontrava espaço nos programas institucionalizados da universidade. Inúmeros fatores contribuíram para que o programa fosse organizado a partir da reforma de um projeto disciplinar já existente na instituição. 
Entre esses fatores, as políticas de educação superior daquele momento de incentivo à aposentadoria foram decisivas.

Outro programa se estruturou pela vontade/necessidade de fortalecer uma área de pesquisa que não encontrava espaço nos programas consolidados diante de uma política de esvaziamento da educação superior pública na década de 1990 e, entretanto, hoje, ocupa um espaço de destaque na universidade; ou seja, o protagonismo dos sujeitos envolvidos surge aqui como fator decisivo no contexto da universidade. A ideia de prestígio das áreas de conhecimento está intrinsecamente relacionada com o contexto social e histórico. Diante dessa compreensão, parece fundamental o papel prospectivo e propositivo do conhecimento produzido no seio das universidades.

Por último, chama a atenção o fato de dois programas serem anteriores à instituição da Área Multidisciplinar, criada em 1999. Esses programas foram avaliados e reconhecidos, no primeiro momento, por pareceristas ad hoc, sem a presença de um documento de área com princípios e metas como os que existem hoje. Por um lado, esses programas foram pioneiros, influenciaram e corroboraram o crescimento expressivo da área. Por outro lado, acompanharam as mudanças, algumas delas denominadas de "conquistas" pela própria Capes (2009). As mudanças ocorridas - tanto no âmbito da Capes de maneira geral quanto, de forma mais específica, na criação da Área Multidisciplinar, que, em 2008, passou a ser designada de Área Interdisciplinar, compondo a Grande Área Multidisciplinar - tiveram influência direta na implementação e consolidação dos programas. O protagonismo de alguns e a experiência acumulada por todos os programas têm influenciado de forma decisiva as políticas de pósgraduação voltadas aos programas interdisciplinares.

No caso do GIDP, o relato é semelhante no que diz respeito à forma de organização inicial. A existência de grupos consolidados em pesquisas cujas temáticas necessitavam de olhares multi e interdisciplinares, grupos inicialmente marginalizados, abriu espaços e possibilidades para uma estrutura reconhecida. 
Em síntese, os programas são constituintes e constituidores de movimentos locais e globais, principalmente de mudanças nos modos de pensar e fazer o conhecimento e a ciência. No caso brasileiro, a Rio92 foi um dos grandes movimentos internacionais que lançaram luzes à elaboração das propostas. As políticas de expansão da educação superior brasileira, em especial da pós-graduação, foram identificadas como o movimento local que teve influência preponderante na configuração dos programas. No caso do programa da Universidade do Arizona, as mudanças globais e os problemas locais com a água foram identificados como fatores centrais na dinâmica constituidora do programa.

O protagonismo e a perspectiva visionária dos sujeitos envolvidos, principalmente professores/pesquisadores foi decisiva para a estruturação dos programas analisados. Por fim, as áreas de que se ocupam das propostas (ambiental e de desenvolvimento) se colocam na fronteira dos conhecimentos disciplinares, o que implica diálogos interdisciplinares.

No âmbito interno das universidades, a estrutura administrativa, com pouca ou nenhuma flexibilidade para promover espaços de diálogo entre áreas consideradas diversas, também parece ser um dos desafios dos programas ao agregar professores/pesquisadores de diferentes áreas do conhecimento e, consequentemente, de diferentes departamentos acadêmicos.

A dificuldade com a estrutura departamental é colocada tanto pelos interlocutores quanto nos documentos. No caso dos programas brasileiros, a análise das propostas foi ilustrativa:

A estrutura departamental vigente representa uma barreira ao alcance deste objetivo posto [formar pesquisadores voltados à temática ambiental]. A estrutura em departamentos formados por especialidades se mostra inadequada e dificulta o diálogo interdisciplinar (P-2).

Em sendo um programa envolvendo tantas e distintas unidades acadêmicas, é difícil manter a referência institucional, o que, se não for bem administrado, traz prejuízos à própria convivência e à ambiência acadêmica, imprescindivel e vital em qualquer programa de pós- 
graduação (P-3).

Durante o ano letivo de 2007, não ocorreu ingresso de estudantes, pois a Câmara de Ensino e Pós-Graduação, com interpretação equivocada, alegou que o curso deveria ser sediado em apenas uma unidade da universidade, e não como planejado inicialmente, em uma articulação entre quatro unidades $(P-7)$.

A estrutura departamental das universidades traz consigo uma concepção de conhecimento, ciência e método que privilegia a fragmentação e a dualidade. Dessa forma, os programas, na sua maioria construídos na sua gênese para serem alocados fora dos departamentos e/ ou unidades acadêmicas com vista a facilitar o diálogo entre áreas e disciplinas diversas por opção teórico-metodológica, não suportam as pressões impostas pela estrutura das universidades. Ou seja, a tensão se encontra entre programas interdisciplinares com concepções de conhecimento, ciência e método que se filiam a um movimento do fazer e do pensar o conhecimento para além das fronteiras disciplinares, reconhecidos e legitimados pela Capes e pelas estruturas das universidades.

As diversas instâncias da estrutura administrativa das universidades não barram as propostas (pois permitem e reconhecem os programas), no entanto, o engessamento das estruturas acaba limitando as propostas e até mesmo criando dificuldades para que elas possam, efetivamente, consolidar concepções voltadas à produção de conhecimento interdisciplinar. 0 que se pondera aqui é o fato de que os departamentos não podem se tornar entraves às propostas que buscam diálogos entre áreas consideradas distintas. A estrutura do departamento pode e deve incentivar diálogos e promover espaços coletivos, a exemplo do que ocorre nos grupos de pesquisa e nos institutos.

Por fim, cabe ressaltar que foi possivel identificar um movimento duplo nos contextos analisados: de um lado, áreas que se colocam nas fronteiras disciplinares, nas quais o diálogo entre diferentes disciplinas parece estar na origem das propostas; de outro, a produção de conhecimento e a experiência de professores/ 
pesquisadores nessa área parecem ter evidenciado e/ou (re)forçado a abertura de espaços institucionais antes não existentes, tanto no âmbito das universidades, em particular, quanto no âmbito da Capes, de maneira geral. Esses movimentos não são isolados nem ao menos descontextualizados, eles fazem parte de um momento histórico em que os temas socioambiental e do desenvolvimento ocupam lugar de destaque em diferentes espaços e sob diferentes concepções. Cabe, entretanto, atenção especial aos processos regulatórios, pois o protagonismo dos sujeitos envolvidos pode consolidar concepções já estabelecidas ou questioná-las.

\section{Considerações Finais}

Com o intuito de compreender os contextos e pretextos de programas interdisciplinares, o objetivo deste estudo foi analisar programas de pós-graduação interdisciplinares, buscando captar especificidades dos contextos e pretextos dos programas confrontados. Nesse intento, é possível afirmar que são, os programas analisados, parte de um contexto de questionamentos e mudanças nas formas de pensar e fazer ciência. Os programas são compreendidos como parte do movimento crescente da ciência que busca repensar a fragmentação e a dualidade, inclusive na direção de legitimar outros espaços de poder e prestígio e rever a organização de áreas do conhecimento historicamente constituídas.

No âmbito dos programas brasileiros, a Rio-92 destaca-se como um importante evento, um momento de ebulição desses movimentos, tendo se tornado um espaço de discussão e consolidação de novas ideias, principalmente no campo das chamadas Ciências Ambientais e da temática do desenvolvimento. O contexto de mudanças institucionais que vivia a educação superior naquele momento constituiu terreno fértil para muitas das iniciativas lá debatidas. A organização de grupos e espaços institucionais para participação na Conferência e para a sua realização acabou servindo de embrião para muitos dos programas analisados e que hoje são considerados referência na produção científica nesse campo. Ou seja, a realização de um evento 
internacional do porte da Rio-92 contribuiu para alavancar iniciativas e consolidar propostas talvez antes impensáveis. A participação e a inserção de professores/pesquisadores na Conferência é considerada, no âmbito desta investigação, como constitutiva dos programas.

No contexto da universidade norte-americana foi possivel perceber que o programa analisado é parte de uma estrutura administrativa alicerçada na lógica interdisciplinar. Todos os 14 programas que formam o GIDP são integrantes de uma missão da universidade: a interdisciplinaridade. E essa missão é usada, inclusive, como estratégia de marketing, fortalecendo os grupos de projetos ali inseridos.

No cenário mais amplo, foi possivel perceber que os contextos e pretextos analisados são parte de movimentos de mudanças e críticas não apenas no que se refere às formas de fazer e pensar a ciência, mas também no que diz respeito às mudanças nas formas de organização das instituições. É visível, no contexto da expansão da educação superior em países como o Brasil e da massificação em outros, como os Estados Unidos, a implementação de diferentes instituições nas quais o termo inter tornou-se não apenas uma característica comum, mas uma tendência e uma necessidade.

Por fim, as análises revelaram o protagonismo e a experiência consolidada do corpo docente em programas de pós-graduação disciplinares e na pesquisa interdisciplinar. Tal característica foi compreendida como constitutiva dos programas que carregam como marca característica, desde a origem, a experiência acumulada de parte do corpo docente no que se refere às mudanças globais, com foco principalmente nas temáticas do clima e do desenvolvimento.

Recebido em 10/08/2014

Aprovado em 25/08/2014 


\section{Referências}

BORDAS, M. C. A Interdisciplinaridade na Universidade: possibilidades e limites. In: FRANCO, M. E. D. P.; KRAHE, E. D. (Org.). Pedagogia universitária e áreas de conhecimento. Porto Alegre: EdiPUCRS, 2007. p.73-93. (Ries/Pronex).

BOURDIEU, P. O Campo Científico. In: ORTIZ, R. (Org.); FERNANDES, F. (Coord.). Pierre Bourdieu: Sociologia. São Paulo: Ática, 1983. p. 123-155.

CAPES - Coordenação de Aperfeiçoamento de Pessoal de Nivel Superior. CAlnter (Comissão de Área Interdisciplinar). Documento de Área Interdisciplinar Triênio 2007-2009. Brasília, 2009. Disponível em: <http://www.capes.gov.br/avaliacao/documentos-de-area-/3270>. Acesso em: 30 mar. 2009.

CARSON, R. Silent spring. 40th Anniversary Edition. New York: Mariner Books, 2002.

FRANCO, M. E. D. P. Universidade Pública em Busca da Excelência: grupos de pesquisa como espaço de produção de conhecimento. In: FRANCO, M. E. D. P; LONGHI, S. M.; RAMOS, M. da G. (Orgs.). Universidade e pesquisa: espaço de produção de conhecimento. Pelotas: Editora e Gráfica UFPel, 2009.

GIDP - Graduate Interdisciplinary Programs. By the Numbers - 2009. Disponivel em: <http://gidp.arizona.edu/system/files/GIDP_by_the_ Numbers_2009.pdf>. Acesso em: 10 maio 2011.

About GIDP. Disponivel em: <http://gidp.arizona.edu/about>. Acesso em: 1 ago. 2014.

GIROUX, H. A. Teoria crítica e resistência em educação: para além das teorias de reprodução. Petrópolis: Vozes, 1986.

MOROSINI, M.; FRANCO, M. E. D. P. Brazilian Higher Education polices and new challenges un international cooperation. In: 22a ANUAL EAIR FORUM, Berlin, Frei Universtitad, Germany, 6-9 September, 2000. 15 p. 
RAYNAUT, C. Interdisciplinaridade: mundo contemporâneo, complexidade e desafios à produção de conhecimentos. In: PHILIPPI JR., A.; NETO, A. J. S. Interdisciplinaridade em Ciência, Tecnologia e Inovação. Barueri, SP: Manole, 2011.

SOUSA SANTOS, B. Pela mão de Alice: o social e o político na pósmodernidade. 4. ed. São Paulo: Cortez, 1997. 